\title{
Editorial
}

\section{"CLOSING THE LOOP” OF THE CIRCULAR ECONOMY AND COVID19}

The COVID-19 pandemic has placed considerable pressure on the waste management system and has challenged the Circular Economy, highlighting the already clearly evident contradictions and fragilities of the system.

The acknowledged principles underlying the Circular Economy are based on a series of assumptions including a limited availability of natural resources and a need to restrict emissions that impact on an environment at risk of being irreversibly compromised. Accordingly, the resulting aim of the Circular Economy is to maintain the value of products over an extended period of time, to reduce the use of non-renewable primary materials and to minimise impacts by preventing the generation of wastes ("Zero Waste") through use of environmentally-friendly technologies.

Wastes therefore have been identified as a boundless new source of resources combined with the dual perspective of removing the problem of providing for their disposal. Thus, following establishment of the Circular Economy through the defining of measures of intervention and the enactment of national and international legislation, wastes have been definitively legitimised to substitute for non-renewable resources. This process had indeed already been launched worldwide through the "Kobe 3Rs Action Plan" (2008), with wastes evolving from useless foul-smelling dross into pieces of gold. And following decades of striving to 'close the loop' (Otterpohl et al., 1997) with the aim of fostering a sustainable closure of the material loop, conscious of the limitations of the industrial cycles and recirculation, all at once the world economy - in severe recession and seeking new development models - 'copied and pasted' this circular vision, defining it "an opportunity to rethink our economic future" and adopting the same to decline a new means of ensuring the future survival of the planet. The Circular Economy framework is nowadays seen as a key approach to achieve some of the United Nations Sustainable Development Goals (SDGs), such as goal 12- to ensure sustainable consumption and production patterns.

However, this attempt to portray the 'new' economy as the solution for all environmental concerns and promoter of a generational solidarity also serves to highlight both the original sin and potential Achilles heel of the system. Although worthy of having introduced the concept of the circularity of resources worldwide, this approach, globally deemed perfect (economically, socially and environmentally), has however failed to succeed to stimulate the marked change required to detach itself from the need for a conti- nual rise in use of consumer goods and supply of services to affirm global development.

Indeed, SDGs, in conjunction with the aims of a Circular Economy, are directed along a similar trend, as depicted by sustainable development goal n.8, the aims of which translate into a global GDP growth of $3 \%$ per year (Hickel, 2019). In this context, the global use of primary materials is projected to almost double from $89 \mathrm{Gt}$ in 2017 to $167 \mathrm{Gt}$ in 2060 , where the strongest growth in material use will occur in emerging and developing economies. The high demand for materials implies a similar rate of increase in use of both primary and secondary materials, although the high labour costs of secondary technologies, the need to continually update recycling technologies and the somewhat scarce quality of some fractions hamper a rapid and solid penetration of secondary materials despite an increase of competition in the area of recycling (data from OECD, 2019). The recycling industry, currently a tenth of the size of the mining sector in terms of GDP share, is likely to become more competitive and grow, although remaining a much smaller industry than the mining of primary materials.

For specific municipal waste streams, the market of secondary materials has certainly offered development opportunities to new recycling industries, although the combined effect of a rise in separate collection, the closure of a series of international markets and an ongoing trade war between China and the US, have all complicated the exploitation of growing volumes of materials. This excess supply has resulted in a depreciation of secondary materials (e.g.: the average price of cardboard has plummeted by $90 \%$ over the last year), and thus in a difficulty to close the cycle, at times even forcing a return to processing the materials as wastes (Maragoni, 2020).

Whatever the reason, an increase in waste production will be witnessed in forthcoming decades, particularly in those countries in which the Circular Economy is proposed as a development model of extreme efficacy in overcoming disparities. In 2016, a total of 2.1 billion tons of municipal wastes were produced worldwide, with a predicted $70 \%$ increase by the year 2050 (the

Sub-Saharan Africa is expected to see waste level approximately triple); the sole EU produced a total of $5 \mathrm{t}$ per inhabitant, $4 \%$ of which were hazardous waste (World Bank and Eurostat data).

Despite the efforts made to unite the starting point with the end point of this material loop, unfortunately, closure of the Circular Economy loop will only prove feasible if we finally concede that the Circular Economy as envisaged to 
date does not provide a solution to the waste problem and does not contribute towards reducing disparities. We risk witnessing a further increase in forms of environmental colonialism: still today, electronic wastes originating from a series of industrialised nations (including the US, France, Germany, Switzerland, Korea and the Netherlands) end up in the Agbogbloshie landfill (Ghana). Indeed, Africa, in spite of the key statement made during the Bamako Conference (1991) against the importation of electronic wastes, continues to act as sink for a dubious separate collection of electronic wastes from throughout the world, with Ghana and Nigeria leading the depressing rank of importer nations (Poltronieri, 2019).

However, to identify waste recycling as the focal point of a Circular Economy whilst at the same time advocating the aim of Zero Waste is a sort of oxymoron.

The contradictions and fragilities highlighted have become even more evident during the recent COVID-19 pandemic.

Although a mean decrease of $20 \%$ was registered in municipal solid waste during the lockdown period, largely due to the lack of waste generated by traders and the restaurants field, the slowing down of a series of industrial activities and the shutting down of yet others, together with the closure of foreign markets have prevented separately collected wastes from finding an appropriate collocation. This in turn has led to a saturation of storage both in recycling plants and, in some cases, in thermal treatment plants. Contrary to both the latter and to landfills however, recycling fails to provide an outlet for the waste materials, that must be collected in any case.

An inverse situation has been created with regard to medical wastes, which in some contexts have increased three-fold, with the related management being on the verge of collapsing due to the unexpected deluge of volumes to be handled. The demagogic choice made by many European countries to limit (or even prevent), based on the principles of the Circular Economy, the construction of facilities, is at risk of becoming crucial in a sector in which thermal treatment plays a key role in guaranteeing safety and protection.

During the post-pandemic period, we will also need to deal with the disposal of personal protective equipment (face masks, gloves, plexiglass shields) and other plastic materials used in public spaces (plastic beakers, cutlery and cups used in the hospitality and other industries), items manufactured using mixed materials and deemed indispensable in the start-up of economic activities, to enable people to return to the office or to factories, to sit in a restaurant or to access retail shops.

There is therefore an evident conflict between the pathway identified by the Circular Economy (e.g.: European Strategy for Plastics in a Circular Economy, 2018) tending towards a reduction of single use plastics, and the need to increase use of the latter over the forthcoming months, or even years. In Italy, the quantities of materials needed by workers throughout the various sectors, taking into account that some will continue to work from home, has been estimated in the use of more than 900 million face masks each month in the work place, another 100 million during travel, and more than 500 million gloves. It has also been estimated that schools will use a total of 400 million face masks each month, in addition to single-use lunch boxes with plastic plates and cutlery (estimates from Politecnico di Torino).

Solutions to these evident conflicts and contradictions have been put forward by the waste management sector involved in dealing with issues raised by the pandemic, in the interest of pursuing an efficient and non-demagogic closure of the Circular Economy loop.

Concomitant to the development of recycling plants aimed at improving performance and better defining End of Waste criteria, it is fundamental that the important contribution provided by the energy from waste sector in recovery of materials and provision of an alternative outlet to recycling, including both sustainable landfilling and geological repository (Cossu, 2016), should be acknowledged: in this way, residues from both recycling and emergencies such as the current COVID-19 pandemic could be allocated final or temporary storage. A system therefore that envisages a return to the land and a more flexible closure of the material loop, thus reinforcing the concept of resilience held so dear by the Circular Economy.

Effectively, we merely need to acknowledge that the Circular Economy is not perfect and does not comprise a superior form of 'ethics' to those adhered to by previous economic models.

\author{
Maria Cristina Lavagnolo \\ University of Padova, Italy \\ mariacristina.lavagnolo@unipd.it
}

\section{REFERENCES}

Cossu R. (2016). Back to Earth Sites: From "nasty and unsightly" landfilling to final sink and geological repository. Waste Management 55, 1-2; http://dx.doi.org/10.1016/j.wasman.2016.07.028

Hickel J. (2019). The contradiction of the sustainable development goals: Growth versus ecology on a finite planet. Sustainable Development, 27 (5) 873-884. https://doi.org/10.1002/sd.1947

Maragoni A. (2020). Quale nuovo equilibrio per le filiere del riciclo? Staffetta Quotidiana, on line magazine. Available on line at: https:// www.staffettaonline.com/articolo.aspx?id=344211.

Otterpohl R., Grottker M., Lange J. (1997). Sustainable water and waste management in urban areas. Water Science and Technology, 35 (9) 121-133. https://doi.org/10.1016/S0273-1223(97)00190-X

Poltronieri F. (2019). In questa infernale discarica tossica del Ghana finiscono i nostri rifiuti elettronici. EURONEWS. Available on line at: https://it.euronews.com/2019/07/26/in-questa-infernale-discarica-tossica-del-ghana-finiscono-i-nostri-rifiuti-elettronici 